\title{
AVALIAÇÃO DE USO PÚBLICO DAS ÁREAS DAS LAGOAS AZUL E BONITA - PARQUE NACIONAL DOS LENÇÓIS MARANHENSES
}

Cláudio Eduardo de Castro ${ }^{1}$

RESUMO: O Parque Nacional dos Lençóis Maranhenses teve seu plano de manejo elaborado há mais de 10 anos e muitas das dúvidas sobre os aspectos dos usos ficaram por serem resolvidos, mas não o foram. Nesse sentido, a direção do Parque, o Ministério do Turismo e a Universidade Federal do Maranhão firmaram convênio para averiguar a qualidade do uso das lagoas, em seus aspectos ambientais e de satisfação do visitante, bem como da percepção dos impactos de visitação, visando aperfeiçar o manejo do uso público proposto pela Unidade de Conservação. As análises comparativas da água e dos sedimentos das lagoas e as entrevistas mostraram que o uso não vem causando degradação das lagoas e o usuário consome a paisagem sem perceber os impactos causados ao ambiente.

PALAVRAS CHAVE: Parque Nacional dos Lençóis Maranhenses; Percepção Ambiental; Uso Público; Plano de Manejo.

1. As Unidades de Conservação e seu papel de conservação - preservação, o Parque Nacional dos Lençóis Maranhenses - PNLM

As Unidades de Conservação (U.C.) brasileiras têm um papel fundamental na perpetuação dos recursos naturais, dada a acelerada descaracterização desses ambientes causada pela apropriação tecnológica dos meios de produção capitalistas. $\mathrm{O}$

\footnotetext{
${ }^{1}$ Doutorando do programa de poós-graduação em Geogrrafia-Unesp-PP / professor da Uema.
} 
Sistema Nacional de Unidades de Conservação (MMA-IBAMA, 2000 cap1) as define como sendo "[...] espaço territorial e seus recursos ambientais, incluindo as águas jurisdicionais, com características naturais relevantes, legalmente instituídos pelo Poder Público" e os objetivos desses espaços são principalmente os de "conservação" em seus limites definidos, "[...] sob regime especial de administração, ao qual se aplicam garantias adequadas de proteção".

O Parque Nacional dos Lençóis Maranhenses (PNLM), decretado por lei federal (86.060) em 02.06.81 tem área de $155.000,00$ para "[...] a preservação de ecossistemas naturais de grande relevância ecológica e beleza cênica, possibilitando a realização de pesquisas científicas e o desenvolvimento de atividades de educação e interpretação ambiental, de recreação em contato com a natureza e de turismo ecológico" ${ }^{2}$ em ambiente costeiro. Um Parque Nacional (Parna) é uma unidade de proteção integral dos recursos naturais que o integram segundo seus objetivos.

Os Parnas, como unidades de proteção integral, contemplam uma divisão de setores ou zonas "[...] com objetivos de manejo e normas específicos, com o propósito de proporcionar os meios e as condições para que todos os objetivos da unidade possam ser alcançados de forma harmônica e eficaz" ${ }^{3}$. Desta forma a administração do PNLM deve, como rege $0 \S 1^{\circ}$ do artigo 25 da lei SNUC, ser responsável pela administração da unidade e estabelecer normas específicas, regulamentando a ocupação e o uso dos recursos, sendo o plano de manejo o documento mestre a ser elaborado, implantado, avaliado e reelaborado constantemente. O PNLM tem seu plano de manejo (IBAMA/MMA, 2002) adequadamente publicado e minuciosamente elaborado no que concerne aos mais diversos aspectos, mas há uma inconsistência na efetivação do 'quanto de uso' é permitido. Em contrapartida, o número demandado é expressivamente superior ao sugerido no plano, o que vem causando inúmeros impactos negativos, contribuindo assim para o comprometimento de suas funções.

Mesmo havendo sido construído documento que sugere alteração no manejo e na infra-estrutura do parque (MMA-IBAMA, 2006), não se fez levantamentos específicos quanto à relação dos usos e representações dos usuários e nem se quantificou 
exatamente a demanda ecoturística, cuja relação quantidade-qualidade é a mais importante.

Desta forma uma pesquisa que una os conhecimentos existentes à qualidade das representações dos usuários e a quantidade das mudanças necessárias à preservação e a sua repercussão no usuário (sejam de ordem econômica, social, cultural ou da própria motivação do visitante) merecem e precisam ser realizadas.

\section{Os estudos, a fundamentação e sua realização.}

Glenn F. Ross (2002, p.71-2) explica que para entender as representações de meio ambiente no contexto do turismo, compreender o comportamento do turista e, ainda, entender os impactos do uso do ambiente primeiramente é necessário "[...] uma introdução à pesquisa das imagens ambientais do turismo e depois incluir uma visão geral da esfera do mapeamento cognitivo" A interpretação expressa, quando se refere ao foro íntimo do indivíduo, é de difícil apreensão, conforme atesta Tuan (1983, p.152), que lembra que um "[...] sorriso ou contato pode alertar nossa consciência sobre um momento importante. Na medida que estes gestos podem ser observados, eles são públicos. São, entretanto, efêmeros e seus significados estão longe de uma interpretação verdadeira, que não podem proporcionar a base para o planejamento em grupo ou ação. Carecem de firmeza e objetividade de palavras e imagens".

As representações sociais aparecem como uma alternativa ao positivismo reinante nas ciências sociais, como lembrou Minayo (2000, p.43-5). Devemos distinguir as categorias do senso comum como sendo "[...] conceitos usados pelos membros da sociedade para explicar e descrever o mundo onde vivem" ao passo que a ciência se correlaciona aos "fatos sociais" de forma objetiva, baseada na pesquisa empírica sobre fatos sociais, não nos indivíduos. Fato relevante lembrado pela autora é o papel do cientista que deve separar "[...] entre as representações dos fatos dadas pelas idéias que fazemos deles, da "coisa real" ${ }^{4}$ - que é a ciência empírica.

4

Op. cit p.5 
As representações são "[...] fenômenos complexos que extrapolam categorias puramente lógicas e invariantes, organizando-se como um saber acerca do real que se estrutura nas relações do homem com este mesmo real", isto vem alterar a abordagem da pesquisa sociológica (MADEIRA, 1991, p.129). Spink (1995, p.89) mostra-nos que essa nova abordagem não é um olhar sobre a fração do social manifesta pelo indivíduo, nem mesmo, pode-se tomar isso como contraponto ao olhar macro das representações coletivas dos positivistas, trata-se de analisar a complexidade do fenômeno.

As teorias de manejo de áreas naturais preservadas usadas para visitação centralizaram o desenvolvimento de alguns indicadores e estandartização, incluindo atributos semelhantes à densidade de visitantes, sugerindo a influência da visitação (FREIMUND, 2001, p.3). Hoje o limite de uso dessas áreas vem dar resposta às pressões de demanda surgidas nos últimos anos que incluem "[...] a situação geográfica, disponibilização de recursos, filosofia dos responsáveis pela U.C., políticas públicas, além da experiência dos visitantes". O que se quer é solucionar os conflitos gerados, objetivando obter-se uma densidade possível para atender a forma de experiência que o visitante quer vivenciar e a tolerância que seu estilo de vida permite para a proteção do recurso específico, esse conflito só é passível de solução ante a relativização dos indicadores estandartizados e os estudos dos usos, que se dão pelo estudo da representação que têm os usuários.

Os estudos puderam ser efetivados graças a financiamento da Agência Espanhola de Cooperação Internacional - AECI que neste projeto manteve parceria com o Ministério do Turismo, PNLM, Prefeitura Municipal de Barreirinhas, Fundação Sousândrade e Dptº de Geociências da Universidade Federal do Maranhão (UFMA). A avaliação do uso da área da Área Funcional das Lagoas deu-se pelo uso de entrevistas qualitativas, através de 500 entrevistas.

As entrevistas abertas (SPINK, 1995) foram feitas em papel, constando de perguntas objetivas para a qualificação do entrevistado, perguntas abertas, além de roteiro de entrevista, esta opção se justifica pela urgência e necessidade de se pesquisar mais de um ponto ao mesmo tempo, o que em caso contrário exigiria equipamentos e pesquisadores em número maior. As entrevistas foram analisadas segundo a qualidade e depois categorizadas (MINAYO, 2000; BARDIN, 1997), para que se possa entender os 
diferentes simbolismos e representações dos usuários, que servirão para o planejamento de ações necessárias à minimização dos fatores que hoje vêm impactando negativamente o ambiente do parque.

Como forma de iniciar diagnóstico do uso das lagoas para banho, uma parcela dos recursos foram destinados para a análise laboratorial das águas das lagoas que não demonstraram alteração significativa da qualidade, sob o uso e carga utilizados hoje, inclusive, a maioria das análises demonstraram possibilidade de uso das águas para abastecimento sem desinfecção (CASTRO; ANDRADE, 2007). O projeto iniciou-se em julho de 2006 e finalizou-se em junho de outubro de 2007.

\section{Entrevistas, resultados para indicadores de manejo}

As entrevistas revelaram alguns aspectos sobre o uso, os impactos, os desejos e motivações dos usuários, indicando as possibilidades de manejo e o quanto e onde haverá novas relações entre os usos e a necessidade de conservação quando da implementação de ações pela administração do parque. Coriolano (2001, p. 218) ressalta que o espaço turístico é "[...] antes de tudo uma imagem feita pela 'média' e pela representação do usuário... todas cheias de ambivalência, contradições e do duplo movimento entre imaginário e real" ou vice-versa, assim a revelação dessas preferências, limites, motivações e imagens possibilitam o planejar de ações substanciadas no uso e percepção do imaginário, o que diminui a possibilidade de projetos descontextualizados, como normalmente são os que se realizam de fora para dentro, especialmente os de consultorias extemporâneas.

Abaixo relatam-se por item das entrevistas, as categorias e sub-categorias emanadas dos usuários e os comentários referentes as variáveis que se quis obter referentes aos resultados. A primeira questão que se faz menção é a que nos remete às motivações que fizeram com que o visitante escolhesse viajar e visitar o PNLM. Notamos que muitas das pessoas demonstram não focar diretamente sua motivação, relatando coisas das quais se obtiveram seus desejos. Os resultados são maiores que o total de entrevistados, pois foram anotadas todas as manifestações. 
Tabela 1 - O que mais motivou o visitante a vir ao Parque?

\begin{tabular}{lc}
\hline CATEGORIA - Respostas & Quantidade \\
\hline $\begin{array}{l}\text { PAISAGEM - Beleza Natural; Mídia (TV; Filme, novela); } \\
\text { Informações de outras pessoas; Internet }\end{array}$ & 312 \\
\hline Respostas sem vínculo com análise & 202 \\
\hline $\begin{array}{l}\text { ECOTURISMO - Agência de Turismo; Curiosidade; Já } \\
\text { Conhecia; Passeio; Férias e Feriado; Costuma passear } \\
\text { para conhecer U.C.'s; Desejo Antigo. }\end{array}$ & 41 \\
\hline
\end{tabular}

A segunda questão desejou mensurar o grau de satisfação segundo a relação de suas expectativas anteriores à visita, que se relaciona às motivações e desta forma aumenta a abrangência da questão anterior, e a concretização da visita ao PNLM. Esta pergunta classificou em graus a satisfação para agilizar a entrevista e possibilitar maior concretude às respostas pouco eficazes da pergunta 1 .

Aqui podemos notar a excessiva predominância dos motivos que estimulam o visitante: a paisagem. Somente 15, dos 500 entrevistados encontraram satisfação menor que a expectativa. Fica claro que a manutenção da qualidade paisagística dos lençóis é o maior patrimônio para o ecoturismo local.

Tabela 2 - Qual o grau de satisfação do visitante com a visita.

\begin{tabular}{lc}
\hline Respostas & Quantidade \\
\hline Superou muito & 73 \\
\hline Mais que esperava & 202 \\
\hline Exatamente o que esperava & 210 \\
\hline Menos que esperava & 14 \\
\hline Muito menos que esperava & 1 \\
\hline
\end{tabular}

A terceira questão vem revelar quais os aspectos positivos contribuíram para a satisfação relatada nas respostas anteriores, garantindo especificidade numa análise pormenorizada do imaginário que se manifestou na satisfação.

Tabela 3 - O que foi mais significativo para o grau de satisfação do visitante.

\begin{tabular}{lc}
\hline Respostas & Quantidade \\
\hline Belezas Naturais & 318 \\
\hline Conservação do PNLM & 101 \\
\hline Aventura/Passeio & 55 \\
\hline Palestras & 35 \\
\hline Tranqüilidade & 28 \\
\hline
\end{tabular}

\footnotetext{
${ }^{4}$ O PNLM incluia na entrada dos veículos, uma palestra ilustrativa sobre Unidades de Conservação, os ecossistemas existentes no PNLM e o uso público.
} 
Como perguntar somente sobre a satisfação e o que contribuiu para tal é apenas uma face da moeda, e preocupados com os impactos negativos vários que contribuem com a visitação, ainda na minimização e organização desses impactos, perguntamos quais os aspectos os entrevistados consideraram negativos para a satisfação de sua visita.

Tabela 4 - Que aspectos o visitante considerou negativo em sua visita.

\begin{tabular}{|c|c|}
\hline Respostas & Quantidade \\
\hline Nenhum & 210 \\
\hline \multirow{2}{*}{$\begin{array}{l}\text { INFRA-ESTRUTURA (trade turístico): Dificuldade de acesso ao } \\
\text { PNLM (trilha); Demora e precariedade da infra-estrutura da balsa } \\
\text { (banheiro; lanchonete; iluminação deficiente; falta de colete); Falta } \\
\text { de infra-estrutura da cidade (respectivamente) }\end{array}$} & $60 ; 54 ; 41 ;$ \\
\hline & TOTAL 155 \\
\hline Poluição dentro do PNLM & 30 \\
\hline Sol Forte & 10 \\
\hline \multirow{2}{*}{$\begin{array}{l}\text { SERVIÇOS: População local despreparada; Proibição de consumo } \\
\text { de bebidas alcoólicas; Tempo curto de visitação; Falta de esportes } \\
\text { radicais; Excesso de exercício físico; Despreparo dos guias; } \\
\text { Preços altos (respectivamente) }\end{array}$} & $\begin{array}{c}9 ; 6 ; 4 ; 3 ; 8 ; 3 ; \\
5 \\
\end{array}$ \\
\hline & TOTAL 38 \\
\hline \multirow{2}{*}{$\begin{array}{l}\text { PNLM: Falta de Posto de Apoio no PNLM (banheiro; lanchonete e } \\
\text { outros); Demora na sede do IBAMA; Falta de posto medico dentro } \\
\text { do PNLM; Falta de fiscalização do IBAMA; Excesso de visitantes; } \\
\text { Animais dentro do parque (respectivamente) }\end{array}$} & $\begin{array}{c}24 ; 2 ; 4 ; 4 ; 14 \\
6\end{array}$ \\
\hline & TOTAL 54 \\
\hline
\end{tabular}

Muitos não consideraram que houve contribuição negativa significativa, mas a grande parte dos entrevistados relatou algum tipo de negatividade, seja ela advinda da infra-estrutura, da receptividade, dos serviços e os mais diversos fatores. Podemos considerar que fica claro que o PNLM e os serviços oferecidos na localidade influenciam negativamente o uso turístico a que se propõe o Plano de Manejo.

Uma parte destacada da entrevista foi o diagnóstico quanto ao uso das lagoas, onde um bloco de questões pretendeu revelar alguns aspectos importantes para o manejo e ações preventivas. Diagnosticou-se assim o tempo que o visitante permaneceu na lagoa e se ele o considerou satisfatório, bem como se ele sentiu a sensação de que o uso é excessivo, pela sensação de 'multidão' e se percebe impactos negativos. 
Tabela 5 - Tempo que o visitante permaneceu na área das lagoas.

\begin{tabular}{lc} 
Respostas & Quantidade \\
\hline 2 horas & 140 \\
\hline 3 horas & 217 \\
4 horas & 90 \\
\hline 5 horas & 8 \\
\hline ou mais horas & 3 \\
\hline
\end{tabular}

Tabela 6 - Como o visitante se sentiu em relação ao número de pessoas nas Lagoas.

\begin{tabular}{lc} 
Respostas & Quantidade \\
\hline Caberia muito mais gente & 30 \\
\hline Caberia mais gente & 64 \\
\hline Número confortável de pessoas & 314 \\
\hline Com mais gente do que deveria & 83 \\
\hline Com muito mais gente do que esperava & 9 \\
\hline
\end{tabular}

Tabela 7 - Que impactos a visitação pode causar ao ambiente.

\begin{tabular}{lc}
\hline Respostas & Quantidade \\
\hline Nenhum & 222 \\
\hline Lixo ('bituca' de cigarro; restos de comida) & 123 \\
\hline Poluição das lagoas (urina; filtro solar; animais domésticos) & 79 \\
\hline Existe & 45 \\
\hline Destruição da vegetação & 17 \\
\hline Assoreamento das lagoas & 10 \\
\hline Poluição $\left(\mathrm{CO}_{2}\right)$ & 4 \\
\hline
\end{tabular}

A permanência na área das lagoas é via de regra de poucas horas, tal fato não impede a satisfação dos usuários, conforme atestado em questão anterior. O sentimento de 'multidão' tão preocupante para o suo de ambientes destinados ao turismo, especialmente o de natureza, foi pouco relatado, mesmo assim é significativo que 92 pessoas pensem que o número está acima do que possibilita sua inserção num espaço natural. $O$ fato da permanência de poucas horas satisfazer as motivações da visita foi justificada muitas vezes pela excessiva radiação solar na área das dunas, pelo calor e pela ausência de atendimento às necessidades pessoais como sanitários, água e alimentação, mas que estes itens foram relacionados de formas distintas. Os sanitários foram considerados essenciais e indispensáveis, ao passo que uma área de recepção com disponibilidade de água e alimentação foi considerada uma 'facilidade' já que muitos 
deles levam lanche e água, e muitos dos guias e monitores prestam esse serviço, levando água em sua mochilas. PNLM?

Tabela 8 - Quais sugestões você gostaria de dar para melhorar a melhoria da visitação no

\begin{tabular}{lc}
\hline Respostas & Quantidade \\
\hline Nenhum & 107 \\
\hline INFRA-ESTRUTURA & 221 \\
\hline SERVIÇOS & 67 \\
\hline PNLM & 126 \\
\hline
\end{tabular}

Quanto à percepção de poluição, os entrevistados dividem-se quase à metade dos que a percebem ou não. Sendo que o lixo é a poluição mais citada, igualmente o que se constatou em outros trabalhos deste tipo (TAKAHASHI, 1998; WWF-BRASIL, 2001; MITRAUD, 2002; CASTRO, 2004). Porém algumas respostas conduzem-nos às consequências do uso excessivo, como perda da biodiversidade e do recurso usado pelo turismo. Uma questão foi colocada, de forma aberta, aos entrevistados, para que livremente dissessem o que eles gostariam que melhorasse para melhor satisfazer a visitação, desta forma, as questões anteriores podem ser associadas mais precisamente ao universo perceptivo do entrevistado. Das três grandes categorias já distinguidas anteriormente, a infra-estrutura local e as do parque foram as mais significativas.

As sugestões demonstraram que a infra-estrutura é a mais relatada, confirmando as respostas à questões anteriores, onde os banheiros na área de estacionamento das 'toyotas', na passagem do rio Preguiças, no atendimento às necessidades turísticas na cidade foram relatados. Estes itens devem fazer parte da agenda local de discussão do manejo do PNLM e sua relação com o turismo e suas conseqüências nos aspectos do espaço local, que vem polarizando a cidade de Barreirinhas na região nordeste do estado do Maranhão e atraído população de várias áreas. Quanto aos serviços, o relato de um certo número, relaciona-se aos serviços locais da cidade, mais especificamente os do comércio e os do trade turístico.

\section{Concluindo uma fase para planejamento e manejo.}


As entrevistas demonstraram que a paisagem vem oferecendo uma satisfação ao visitante, ao mesmo tempo que uma significativa parcela considera que há geração de lixo e precariedade da infra-estrutura local e das responsabilidades do PNLM. Este item força a tomada de decisão dos gestores para que a Educação Ambiental estabeleça uma 'ponte' entre a satisfação proporcionada pela paisagem procurada pelo usuário e a percepção dos impactos, levando a uma relação saudável entre uso-preservação.

É imprescindível que os serviços prestados pelos monitores ambientais, os funcionários do parque, a população local e os diretamente envolvidos com o turismo devem integrar-se aos paradigmas de uma boa relação entre a geração de renda, o uso dos recursos abrigados nos limites do parque e a manutenção desses recursos. Para tal, programas devem ser elaborados com várias finalidades e clientelas, em parcerias firmadas entre o órgão gestor do parque, as comunidades residentes, o trade turístico, o poder local, os meios de comunicação local, as cooperativas e organizações sociais.

O PNLM deve implementar a estruturação de serviços de recepção aos visitantes que atendam $100 \%$ da demanda, com estruturação de área cuja arquitetura se inclua à produção local do espaço, com a finalidade de acelerar os processos de valorização do parque que possa, além de servir como consumo da paisagem, construir o paradigma da sustentabilidade. Nesse sentido deve-se também fortalecer as relações locais com os agentes de turismo e a sociedade, visando integrar os serviços a práticas ambientais que contribuam para a manutenção do equilíbrio da preservação e do uso público dos recursos naturais.

Os resultados das entrevistas demonstram que os índices de pouca percepção de impactos e a alta satisfação das motivações podem criar uma irreversibilidade dos impactos criados pelo uso dos recursos, o que levaria à quase total estagnação do turismo verificado hoje e a degradação do ambiente. Este quadro pode causar impactos negativos à sociedade, uma vem que o uso público proporcionado pela área das lagoas é hoje um fator gerador de renda, cuja conseqüência é a dinamização econômica e aumento da dependência do turismo. Essa relação é imposta pela exuberância da paisagem, mas que precisa ser pensada pelos gestores para a elaboração da política de uso público, com um planejamento focado em uma infra-estrutura que satisfaça as 
necessidades impostas pelas demandas dos usuários em sua complexa relação com a preservação.

\section{BIBLIOGRAFIA}

BARDIN, Laurence. 1997. Análise de Conteúdo. Trad. Reto, L.A; Pinheiro, A. Lisboa; edições 70 .

CASTRO, Cláudio E. 2004. O caminho entre a percepção, o impacto no solo e as metodologias de manejo. O estudo de trilhas do Parque Estadual Turístico do Alto Ribeira - SP. Dissertação de Mestrado apresentada ao programa de Geografia Meio Ambiente e

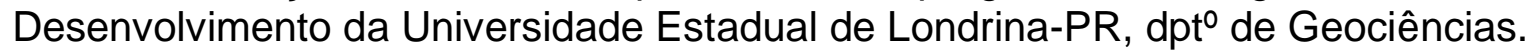

CASTRO, Cláudio E; ANDRADE, Júlio C. S. 2007. Avaliação de uso público das áreas das lagoas Azul e Bonita - Parque Nacional dos Lençóis Maranhenses. In: XII Simpósio Brasileiro de Geografia Física Aplicada: Natureza, Geotecnologias, Ética e Gestão do Território. Natal: UFRN

FREIMOND, Wayne A; Cole, D. N. 2001. I Use density, visitor experience and limite recreation use in Wilderness: progress to dat and Research Needs. In: Visitor use density and Wilderness experience: proceedings. Missoula-MT, PROC, RMRS, p03-08. Ogden, UT-US: Department of Agriculture; Forest Service, Rocky Montain Reserach Statin,.

IBAMA/MMA. Plano de Manejo do Parque Nacional dos Lençóis Maranhenses. BrasíliaDF. 2002

MADEIRA, Margot C. 1991. Representações sociais: Pressupostos e implicações. R.Bras. Est. Pedagógicos, p.129-145. Brasília.

MINAYO, Maria Cecília de Souza. 2000. O desafio do conhecimento: pesquisa qualitativa em saúde. 7e, São Paulo: Hucitec.

MITRAUD, Silvya. 2202. Monitoramento e controle de impactos de visitação. in: Manual de Ecoturismo de base comunitária: Ferramenta para um planejamento responsável. Secção 3, p.285-320, Brasília: WWF.

MMA-IBAMA. 2000 SNUC- Sistema Nacional de Unidades de Conservação. Brasília: MMA-IBAMA. 
MMA-IBAMA. 2006. Levantamento De Dados Relativos a Adequação de Equipamentos Facilitadores e Instrumentos de Apoio do Parque Nacional Dos Lençóis Maranhenses Relatório Técnico Preliminar. Produto 10. Consultora: Sônia Maria Sfair Kinker, PNUD BRANúmero do Contrato - 2004/000848 TR - 109990 Brasília.

SPINK, Mary Jane P. (org). 1983. O conhecimento no cotidiano: as representações sociais na perspectiva da psicologia social. São Paulo, Brasiliense, 1995TUAN, Yi-Fu. Trad. Espaço e Lugar: A perspectiva da experiência. Lívia de Oliveira, São Paulo: Difel.

TAKAHASHI, Leide Y. 1998. Caracterização dos visitantes, suas preferências e percepções e avaliação dos impactos da visitação pública em duas unidades de conservação do Estado do Paraná. Tese de doutoramento, curso de engenharia florestal, UFPR, orientador: Miguel Serediuk Milano, Curitiba.

TUAN 1983. Espaço e lugar. São Paulo, Difel.

WWF-BRASIL. 2001. Uso recreativo do Parque Nacional Marinho de Fernando de Noronha: um exemplo de Planejamento e Implementação. (coord) Sylvia F. Mitraud, série técnica, vol. 8. Brasília: WWF. 